\title{
Study of wind power limit for a network bus
}

\author{
D. García García, M.P. Comech, M. Sanz, J.B. Arroyo, M. García-Gracia \\ CIRCE-Departamento de Ingeniería Eléctrica de la Universidad de Zaragoza \\ C/ María de Luna n 3, 50018 Zaragoza (España) \\ Email: mggracia@posta.unizar.es
}

\begin{abstract}
This paper discusses the influence of the point of common coupling of a wind farm on the voltage fluctuations. The main aim is to deduce the maximum wind power that can be connected taking into account the impact in the electrical network. The weight of a wind farm production in a close up bus is analysed, and the necessity of a dynamic analysis to establish the wind power limit is shown.
\end{abstract}

\section{Key words}

Wind energy, point of common coupling, voltage fluctuations.

\section{Introduction}

When the implantation of wind energy in a specific region is being planned, the definition of the point of connexion of the wind farms (PCC) and the necessary infrastructures to evacuate the produced energy take a great importance. The wind farm impact on the network depends on the point of common coupling. Therefore a suitable selection of the point of common coupling of a wind farm is essential.

The interaction of wind farms and their impact on the voltage quality in the point of common coupling with the grid are an area of increasing concern. The size of the wind farms in any given network often requires an evaluation of the influence from wind fluctuations.

This paper analyses the influence of some parameters of the electrical network on the dynamic behaviour. An electrical network has been simulated in PSS/E [1], applying a gust to the wind farms. The aims of the study are focussed in obtaining the voltage fluctuations based on different parameters from the network, and on its own configuration. The voltage fluctuations are measured according to the IEC 61400-21 [2].

The current norm in Spain [3] establishes, aside from other restrictions, that the power of wind generation will not be superior to $1 / 20$ of the short circuit power of the network at the point of common coupling. In addition, the results of dynamic simulations have been analysed and compared to review the influence of the point of common coupling of a wind farm in the voltage fluctuations.

\section{Description of the dynamic simulations}

The main aim of this analysis is to deduce the maximum wind power that can be connected taking into account the impact in the electrical network.

The simulated network consists on models of conventional generation provided by PSS/E (hydro, thermal and nuclear power plants) and wind turbine models, as much of cage of squirrel [4] as doubly fed induction generator.

To model the wind farm, the mechanical torque is computed for each individual wind generator of the park and then the torque resulting from the addition of all of them is applied to an equivalent model of the wind farm. It was confirmed the dynamic responses of the detailed and the equivalent models were practically the same [5], so the equivalent models have been used in this study to ameliorate the convergence of PSS/E.

Considering the most unfavourable situation, the gust reachs simultaneously all the wind farms of the system. This phenomenon is attenuated by the different wind gust which receives a wind turbine to another one of the same wind farm, and of one more important way, by the variation of the gust from a wind farm to another one due to its different location.

In addition, the power curve of a wind turbine (figure 1) can be separated in two sections, the rank of maximum power and the rank of maximum power variation. The greatest instabilities observed during the simulations match up to the second rank, where a change in the speed of wind involves an important variation in the generated power.

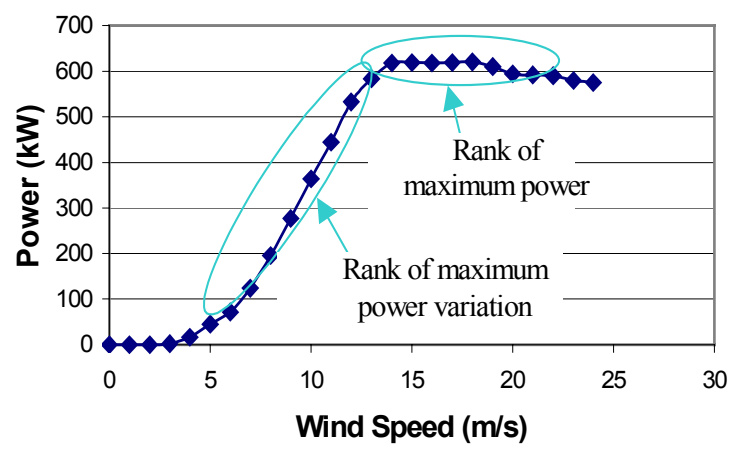

Figure 1. Power curve of a wind turbine of $600 \mathrm{~kW}$. 
The voltage fluctuations produced became higher if the wind speed variation is suited in the rank of maximum power variation. The figure 2 shows the wind gust applied simultaneously to all wind farms, which is based on wind speed measurements.

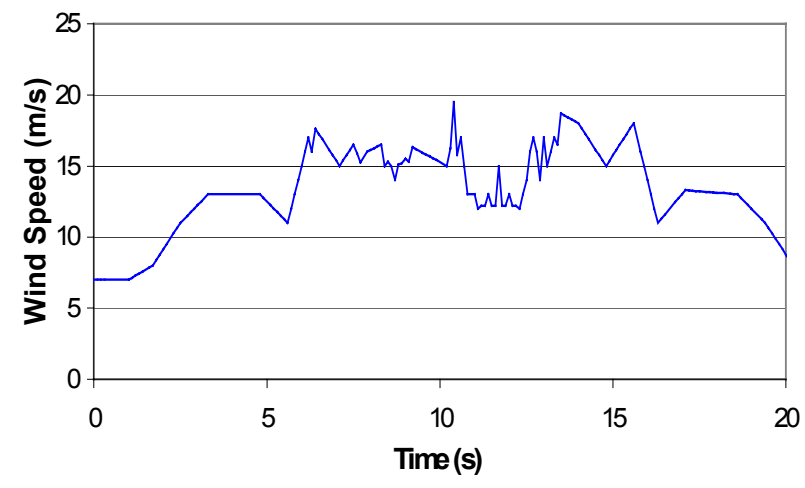

Figure 2. Wind gust.

\section{Study}

In this work, a complex network with more than 1200 buses has been considered. Squirrel-cage induction and double-fed induction generators has been considered. Hydro, thermal and nuclear power plants complete the network.

In the study a weak area of the grid has been considered, which short circuit power is next to $500 \mathrm{MW}$. Therefore, the fluctuations of the generated power are expected to be more significant in this point. According to the spanish norm [1], with this short circuit power the maximum wind power to be installed in a PCC is limited to $25 \mathrm{MW}$ limits.

As it is shown in the figure 3, there are two wind farms (WF1 y WF2). The technology employed in both of them is the squirrel-cage induction generator.

WF1 is installed in the substation PCC1 $(30 \mathrm{kV})$, which connect with the rest of the grid. WF2 is joined to the network in PCC2. The length line which connects PCC1 and PCC2 is noteworthy.

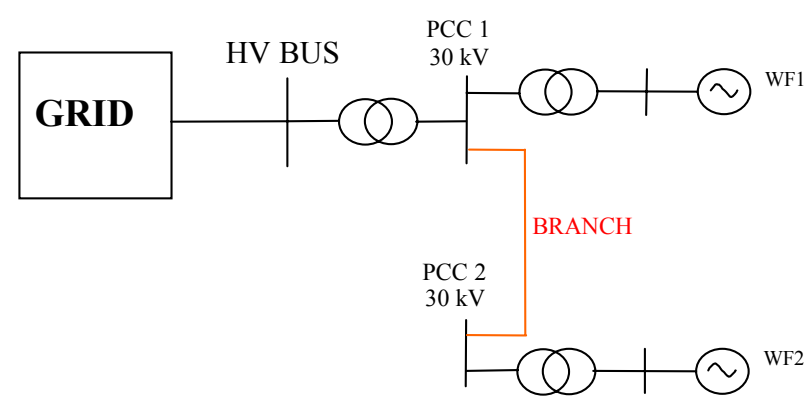

Figure 3. Description of the area.
In the study several numbers of wind turbines connected to the area under test has been simulated. The table 1 shows the powers considered for the wind farms WF1 and WF2. As it can be noted in some cases the norm limit $(\approx 25 \mathrm{MW})$ is exceeded.

Table 1. Wind power installed in the wind farms.

\begin{tabular}{|c|c|c|}
\hline $\begin{array}{c}\text { WF1 } \\
(\mathrm{MW})\end{array}$ & $\begin{array}{c}\text { WF2 } \\
\text { (MW) }\end{array}$ & $\begin{array}{c}\text { TOTAL } \\
\text { (MW) }\end{array}$ \\
\hline 25 & 31,8 & 56,8 \\
\hline 25 & 25 & 50 \\
\hline 25 & 18,2 & 43,2 \\
\hline 12 & 41,6 & 53,6 \\
\hline 12 & 31,8 & 43,8 \\
\hline 12 & 25 & 37 \\
\hline 0 & 25 & 25 \\
\hline 0 & 18,2 & 18,2 \\
\hline
\end{tabular}

\section{A. Wind farms connected to different PCC}

In this section, the wind farms are connected to different points of common coupling (PCC). They are separate by a line whose length is significant, thus the parks must be considered independents and the nominal wind power of each wind farm must be considered in each PCC.

\section{1) Influence of WF2 production on the grid}

First, the impact on the grid of the wind power production by the wind farm WF2 is analysed. The study consists on obtaining the voltage fluctuations in PCC2. The analysis has been carried out considering three nominal powers for the wind farm WF1: $25 \mathrm{MW}, 12 \mathrm{MW}$ or disconnected.

The values of the power production in the wind farms for each case analysed are shown in the table 2 . Furthermore the relation $\mathrm{X} / \mathrm{R}, \mathrm{Scc} / \mathrm{Sn}$ and the voltage fluctuations obtained in PCC2 are indicated in the table.

As it was expected, a rise in the power production of WF2 implies a large diminution on the rate $\mathrm{Scc} / \mathrm{Sn}$ in PCC2 (see table 2). This means a bigger weakness of the point of common coupling, and a growing of the voltage fluctuations. Likewise, the voltage fluctuations are getting worse as the relation $\mathrm{X} / \mathrm{R}$ became lower.

As it has been said before, the gust is applied simultaneously to all the wind farms connected to the grid. Therefore the voltage fluctuations obtained are not realistic, but they are good enough in order to obtain a comparative study.

The voltage fluctuations of WF2 in the point of common coupling versus their relation $\mathrm{S}_{\mathrm{CC}} / \mathrm{S}_{\mathrm{N}}$ are shown in the figure 4 . In this figure, the results obtained for each case 
analysed (production in WF1: $25 \mathrm{MW}, 12 \mathrm{MW}$ or wind farm disconnected) have been represented.

From these results it is clear that a prediction of the wind farm behaviour can not be made taking into account only the quotient $\mathrm{S}_{\mathrm{CC}} / \mathrm{S}_{\mathrm{N}}$. In the same way, the figure 5 shows the voltage fluctuations versus the relation $\mathrm{X} / \mathrm{R}$ in $\mathrm{PCC} 1$ and PCC2.

Table 2. Parameters obtained in PCC2 if each wind farm is connected to different PCC.

\begin{tabular}{|c|c|c|c|c|c|}
\hline & $\begin{array}{l}\text { WF1 } \\
\text { (MW) }\end{array}$ & $\begin{array}{l}\text { WF2 } \\
\text { (MW) }\end{array}$ & $X / R$ & $\mathrm{~S}_{\mathrm{cc}} / \mathrm{S}_{\mathrm{N}}$ & $\begin{array}{c}\text { Voltage } \\
\text { Fluctuation } \\
(\%)[2]\end{array}$ \\
\hline \multirow{8}{*}{ PCC2 } & \multirow{3}{*}{25} & 31,8 & 1,14 & 14,67 & 6,65 \\
\hline & & 25 & 1,20 & 18,08 & 5,03 \\
\hline & & 18,2 & 1,26 & 23,45 & 4,19 \\
\hline & \multirow{3}{*}{12} & 41,6 & 1,16 & 10,96 & 7,07 \\
\hline & & 31,8 & 1,25 & 13,68 & 4,71 \\
\hline & & 25 & 1,32 & 16,78 & 3,55 \\
\hline & \multirow{2}{*}{0} & 25 & 1,45 & 15,22 & 2,76 \\
\hline & & 18,2 & 1,51 & 19,44 & 2,22 \\
\hline
\end{tabular}

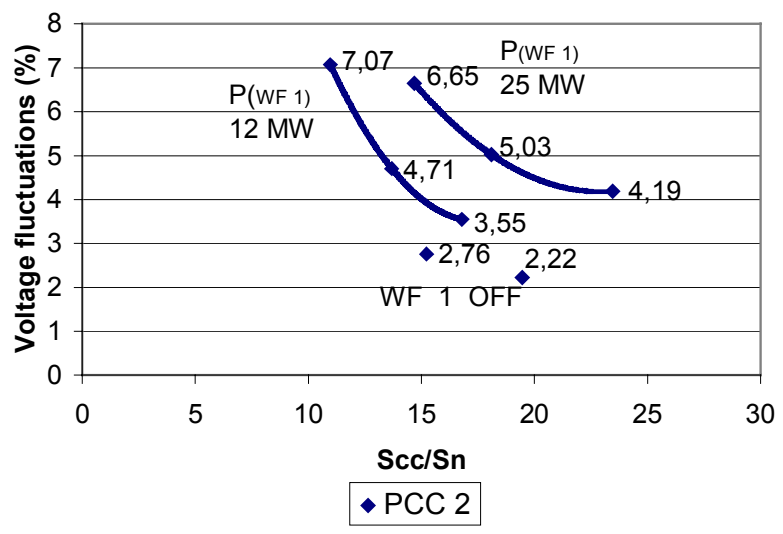

Figure 4. Voltage fluctuations (\%) versus Scc/Sn in PCC2 if each wind farm is connected to different PCC.

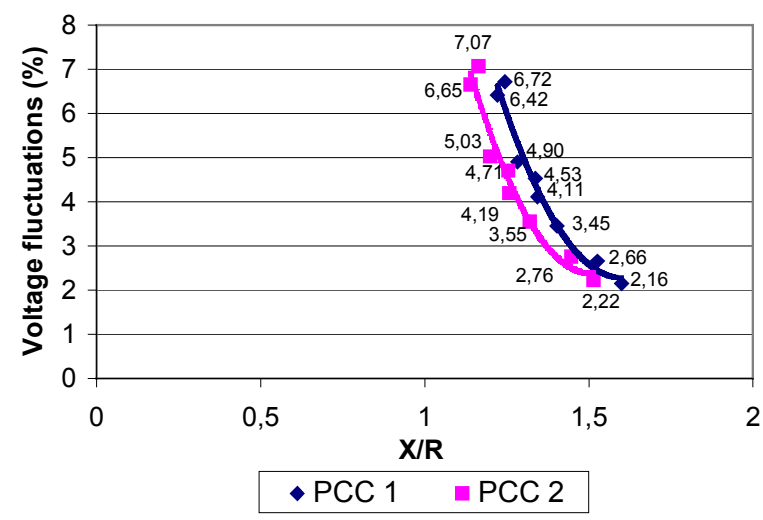

Figure 5. Voltage fluctuations (\%) versus $\mathrm{X} / \mathrm{R}$.

\section{2) Influence of WF2 production on $P C C 1$}

The influence of the wind farm WF2 production on a close up bus as PCC1 is analysed. In the study, the previous productions for the wind farm WF1 $(25 \mathrm{MW}$, $12 \mathrm{MW}$ or disconnected) has been considered.

The voltage fluctuations obtained in PCC1 for the several cases of wind productions in WF2 are shown in the table 3 , where the values of $\mathrm{X} / \mathrm{R}$ and $\mathrm{Scc} / \mathrm{Sn}$ are also given. In the figure 6 the voltage fluctuations in PCC1 versus $\mathrm{Scc} / \mathrm{Sn}$ is depicted.

It must be noted that the voltage fluctuations in PCC1 became higher with increasing power production of WF2 in all cases.

Table 3. Parameters obtained in PCC1 if each wind farm is connected to different PCC.

\begin{tabular}{|c|c|c|c|c|c|}
\hline & $\begin{array}{l}\text { WF1 } \\
\text { (MW) }\end{array}$ & $\begin{array}{l}\text { WF2 } \\
\text { (MW) }\end{array}$ & $X / R$ & $\mathrm{~S}_{\mathrm{CC}} / \mathrm{S}_{\mathrm{N}}$ & $\begin{array}{c}\text { Voltage } \\
\text { Fluctuation } \\
\text { (\%) [2] }\end{array}$ \\
\hline \multirow{8}{*}{ PCC1 } & \multirow{3}{*}{25} & 31,8 & 1,22 & 21,21 & 6,42 \\
\hline & & 25 & 1,28 & 20,71 & 4,90 \\
\hline & & 18,2 & 1,34 & 19,78 & 4,11 \\
\hline & \multirow{3}{*}{12} & 41,6 & 1,24 & 41,52 & 6,72 \\
\hline & & 31,8 & 1,34 & 40,04 & 4,53 \\
\hline & & 25 & 1,40 & 38,92 & 3,45 \\
\hline & \multirow{2}{*}{0} & 25 & 1,53 & ------ & 2,66 \\
\hline & & 18,2 & 1,60 & 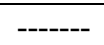 & 2,16 \\
\hline
\end{tabular}

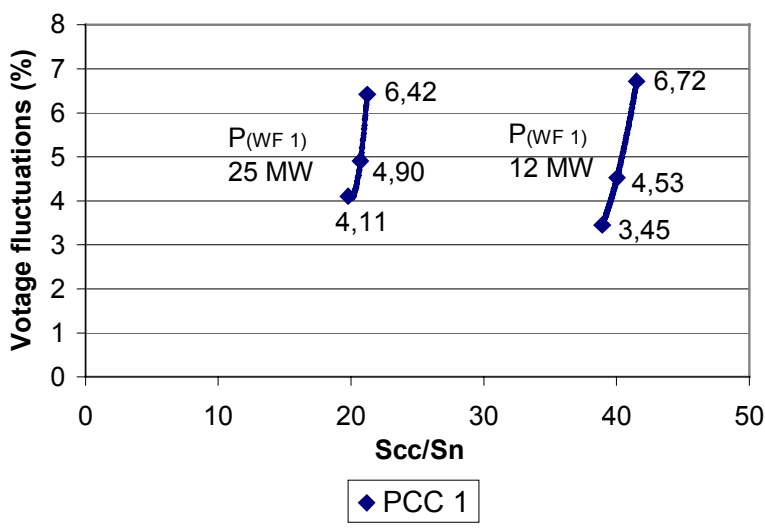

Figure 6. Voltage fluctuations (\%) versus Scc/Sn in PCC1 if each wind farm is connected to different PCC.

\section{B. Wind farms connected to the same PCC}

In this section, the wind farms WF1 and WF2 are considered to be connected to the same point of common coupling PCC1. Thus the value of the nominal power connected in PCC1 is the sum of powers of each park. In the table 4 the voltage fluctuations obtained are shown.

From the figure 7, it can be seen as in this case the fluctuations increase as the relation $\mathrm{Scc} / \mathrm{Sn}$ decreases. 
That is due to the quotient Scc/Sn decreases because Sn is the sum of the contributions of the two wind farms.

Furthermore, according to the spanish norm [2], only the case with WF1 disconnected and WF2 adjusted to 18,2 MW would be legal.

Table 4. Parameters obtained in PCC1 if both wind farms are connected to PCC1.

\begin{tabular}{|c|c|c|c|c|c|c|}
\hline & $\begin{array}{l}\text { WF1 } \\
\text { (MW) }\end{array}$ & $\begin{array}{l}\text { WF2 } \\
\text { (MW) }\end{array}$ & $\begin{array}{l}\text { P }_{\text {TOTAL }} \\
(\mathrm{MW})\end{array}$ & $\mathrm{X} / \mathrm{R}$ & $\mathrm{S}_{\mathrm{CC}} / \mathrm{S}_{\mathrm{N}}$ & \begin{tabular}{|c|}
$\begin{array}{c}\text { Voltage } \\
\text { Fluctuation } \\
(\%)[2]\end{array}$ \\
\end{tabular} \\
\hline \multirow{8}{*}{ PCC1 } & \multirow{3}{*}{25} & 31,8 & 56,8 & 1,22 & 9,30 & 6,42 \\
\hline & & 25 & 50 & 1,28 & 10,97 & 4,90 \\
\hline & & 18,2 & 43,2 & 1,34 & 12,62 & 4,11 \\
\hline & \multirow{3}{*}{12} & 41,6 & 53,6 & 1,24 & 9,24 & 6,72 \\
\hline & & 31,8 & 43,8 & 1,34 & 10,25 & 4,53 \\
\hline & & 25 & 37 & 1,40 & 11,33 & 3,45 \\
\hline & \multirow{2}{*}{0} & 25 & 25 & 1,53 & 16,60 & 2,66 \\
\hline & & 18,2 & 18,2 & 1,60 & 21,47 & 2,16 \\
\hline
\end{tabular}

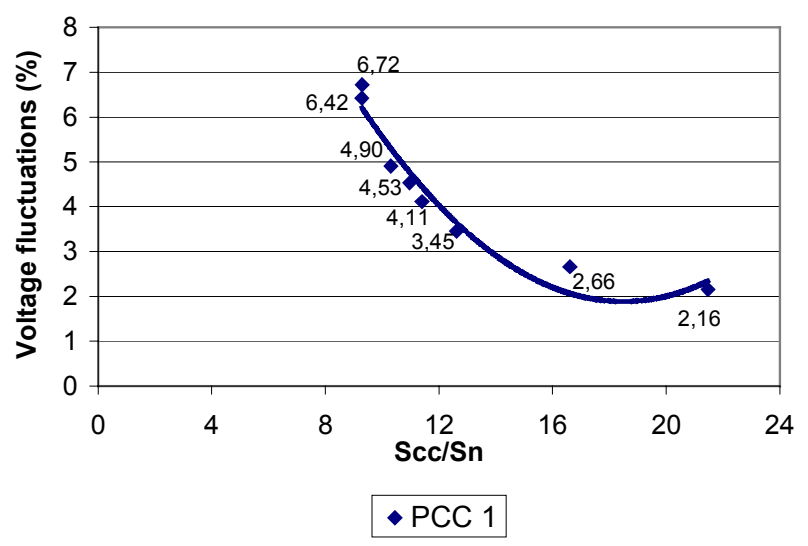

Figure 7. Voltage fluctuations (\%) versus Scc/Sn in PCC1 if both wind farms are connected to PCC1.

\section{Conclusion}

The results obtained shows that the wind farms WF1 and WF2 are not fully independent.

For the case investigated and according to the norm [1], in each PCC it can be installed up to $25 \mathrm{MW}$. That is twice the wind power which could be installed if the two PCC are considered to be the same.

The fluctuations would be too higher if in the proximity there is an important influence of other wind farms. In this case, the norm limit results too permissive. However, in other cases (connexion of several wind farms to the same PCC) the criterion can result too restrictive.

Therefore it is very difficult to determine the wind power limit; too many parameters must be taken into account. The wind power limit is only possible to be established by means of a dynamic analysis.

\section{References}

[1] PSS/E Power System Simulator for Engineering, Power Tecnologies Inc, version 26.2.3.

[2] IEC 61400-21 Wind turbine generators systems - Part 21: Measurement and assessment of power quality characteristics of grid connected wind turbines.

[3] Ministerio de Industria y Energía, "Orden de 5 de Septiembre de 1985”, BOE número 219, año 1985.

[4] A. E. Feijóo, "Influencia de los parques eólicos en la seguridad estacionaria y calidad de onda de redes eléctricas de gran dimensión", Tesis Doctoral, Universidad de Vigo.

[5] J. M. Rodriguez, J.L. Fernández, D. Beato, R.Iturbe, J. Usaola, P.Ledesma, J. Wilhelmi, "Incidence on Power System Dynamics of High Penetration of Fixed Speed and Doubly Fed Wind Energy Systems: Study of the Spanish Case", IEEE Transactions on Power Systems, Vol 17, No. 4 (2002). 